\title{
Proceeding
}

Supplementary Issue: Spring Conferences of Sports Science. 15th Convention and Workshop of the International Network of Sport and Health Science, 5-8 June 2019. University of Las Palmas de Gran Canaria, Las Palmas de Gran Canaria, Spain.

\section{Improving ankle dorsiflexion as a preventive tool for athletes}

\author{
GIOVANNI FALCONE ${ }^{1}$, ANDREA CECILIANI ${ }^{2}$, RICCARDO IZZO³ FRANCESCA D'ELIA $^{1}$ \\ 1 University of Salerno, Italy \\ 2University of Bologna, Italy \\ 3 University Carlo Bo of Urbino, Italy
}

\begin{abstract}
Basketball, such as soccer and volleyball, has the issue to rehabilitation too deep for re athletisation early. The work carried out aims to demonstrate how improving dorsal flexion of the ankle is an excellent tool for the prevention of all injuries for athletes who play basketball. This study has as a sample a group of 12 athletes aged between 16 and 18 years who in the past have found, albeit mildly, problems with the lower limbs linked to reduced mobility of the ankle joint, as demonstrated by the tests that were performed on each subject of the chosen group. The work protocol chosen for the aforementioned group was submitted to each subject three days a week for the duration of two months. The exercises performed were exercises of myofascial release, passive mobility, proprioception and dynamic stretching. All the athletes have meticulously carried out the work protocol and in the end, from the data that emerged, a general improvement of the subjects involved in the protocol can be seen, above all by the most suffering and most frequently exposed to injury. Specifically, the data showed an increase in dorsiflexion of $3.1 \%$ for the left ankle and $6.2 \%$ for the right ankle. Keywords: Basketball; Cuzzolin test; Ankle squat.
\end{abstract}

\section{Cite this article as:}

Falcone, G., Ceciliani, A., Izzo, R., \& D'Elia, F. (2019). Improving ankle dorsiflexion as a preventive tool for athletes. Journal of Human Sport and Exercise, 14(4proc), S654-S663. doi:https://doi.org/10.14198/ihse.2019.14.Proc4.25

Corresponding author. University of Salerno, Italy.

E-mail: fdelia@unisa.it

Supplementary Issue: Spring Conferences of Sports Science. 15th Convention and Workshop of the International Network of Sport and Health Science, 5-8 June 2019. University of Las Palmas de Gran Canaria, Las Palmas de Gran Canaria, Spain. JOURNAL OF HUMAN SPORT \& EXERCISE ISSN 1988-5202

(c) Faculty of Education. University of Alicante doi:10.14198/jhse.2019.14.Proc4.25 


\section{INTRODUCTION}

Today is consolidated the importance of physical activity to health and to prevent injuries, so it is important to know the effects of exercises used (Altavilla, 2018, D'Isanto et al, 2017). Basketball (Altavilla, 2019, D'Isanto et al, 2019), such as soccer (Rago et al, 2017) and volleyball (Raiola, 2014), has to deep the issue of rehabilitation for re-athletisation early. In this way, it is fundamental the base of scientific identity of exercise and sport sciences field (D'Elia et al, 2019, D'Isanto 2019, Raiola et al, 2018,) .An important aspect assume the warm up, it is believed that increased body temperature improves muscle function and elasticity (Altavilla \& Raiola, 2019), increases muscle tissue strength to lacerations, provides a greater connective tissue extensibility within the muscle, decreases muscle viscosity (Szymanski, 2001). Furthermore, motor control and perception has the significant role for the rehabilitation (Ceciliani, 2019, Valentini et al, 2019ab, Raiola 2017, Raiola, Di Tore, 2017). The product of the research focuses on the importance of good mobility of the ankle joint for a basketball player. In fact, a reduction in ankle dorsiflexion could represent a risk factor for anterior cruciate ligament injury, patellar tendinopathy, metatarsal stress fractures and plantar fasciitis, just to name a few. To reduce the risk of these problems, a protocol was designed and administered to assess, both preventively (diagnostic evaluation) and after treatment (performance evaluation), the improvement of the dorsal flexion of the ankle. With the term evaluate, however, we mean the procedure that allows to interpret and judge the measured quantity (variable detected). The evaluation can be defined as a process applied systematically to identify the dimension of the contribution of the various factors related to sport performance (D'lsanto et al, 2019).

The benefits of good mobility, in terms of performance, extend to all aspects of the game as well as to the general health of the athlete who, in any case, suffers globally during an injury period (Altavilla, G. 2016). Sport training is a training process that aims to achieve the highest possible performance under two aspects: quantitative and qualitative (Altavilla \& Raiola, 2018).

\section{METHOD}

It had applied the pairing of short longitudinal investigation of the same sample after the administered physical and test protocol.

The research sample is represented by a group of 12 basketball athletes $(n=12)$ aged between 16 and 18 years $(16.9 \pm 1.1)$ who in the past had lower limb injuries. They have voluntarily participated in this research and have given the consent to participate at this study.

The protocol set up comes from the anthropometric analysis of the subjects and from global tests, first and then analytical, on each athlete.

The tests chosen for the verification of joint mobility were:

\section{Global test: Squat test}

Test developed by Francesco Cuzzolin, strength and conditioning coach for the analysis of the athlete. The test consists in performing the squat in 5 different positions, varying the position of the upper limbs between the positions. The squat test aims to highlight problems of joint mobility and flexibility. The decision to use the squat as the basic movement of the test falls on the poly-articularity of the movement. The athlete must perform the test always following this scheme:1) each position must be repeated 5 times; 2) The execution of the movement must be slow and controlled; 3) You must breathe normally; 4) The knee flexion angle must 
be approximately $60^{\circ}$ (from vertical) $-120^{\circ}$ (at the knee); 5) The feet must be about the width of the shoulders with the points rotated towards the outside of about $\left.15^{\circ}-30^{\circ} ; 6\right)$ The gaze must be facing forward. The position chosen for the reference protocol is Position 1 :

- Arms stretched and crossed fingers.

- Look forward.

- Feet as wide as the shoulders.

- Feet apart at $15-30^{\circ}$.

- Knee's angle max $60^{\circ}$.

\section{Detectable errors}

Lift the ankles; feet in pronation; feet in supination; rotation of the knees. Position 1 is the basic position and we focus mainly on the movements the foot makes (prono-supination), on the mobility of the tibio-tarsal joint, the knee and its possible deviations in varus and / or valgus.

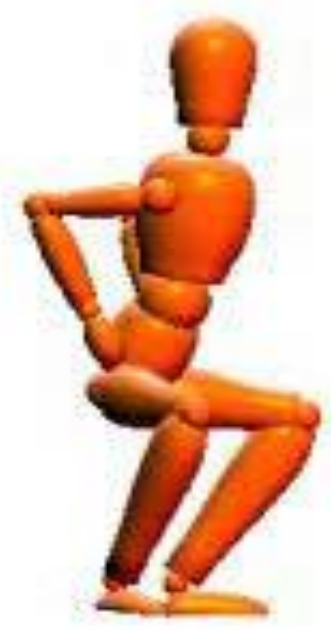

Figure 1. Squat test (Position 1).

The ankle test, or Knee-toWall-Test (KTWT), it's a very simple test that is used to assess the "state of health" of the tibio-tarsal joint. This test involves a forward bending of the knee, such as to be able to bring it into contact with a surface usually facing a wall, and in measuring the distance between the tip of the foot and the surface itself, without ever lifting the heel of the foot reference from the floor. Once the knee has touched the wall, without lifting the heel-lateral foot heel, the distance between the tip of the foot and the wall itself will be indicative of the degree of dorsal flexion of the examined tibio-tarsal joint. A distance from the wall of less than $6 \mathrm{~cm}$ indicates a restriction in the movement of dorsiflexion of the foot; the distance between 6 and 10 $\mathrm{cm}$ shows a probable ankle stiffness; a result between 10 and $12 \mathrm{~cm}$ is considered an indicator of an average tibio-tarsal mobility; a result higher than $13 \mathrm{~cm}$ shows a marked mobility of the ankle or very probably a laxity of the same one.

\section{Detectable errors}

The heel comes off the ground; the foot goes into inversion or eversion; knee launch or worth when trying to touch the wall. 


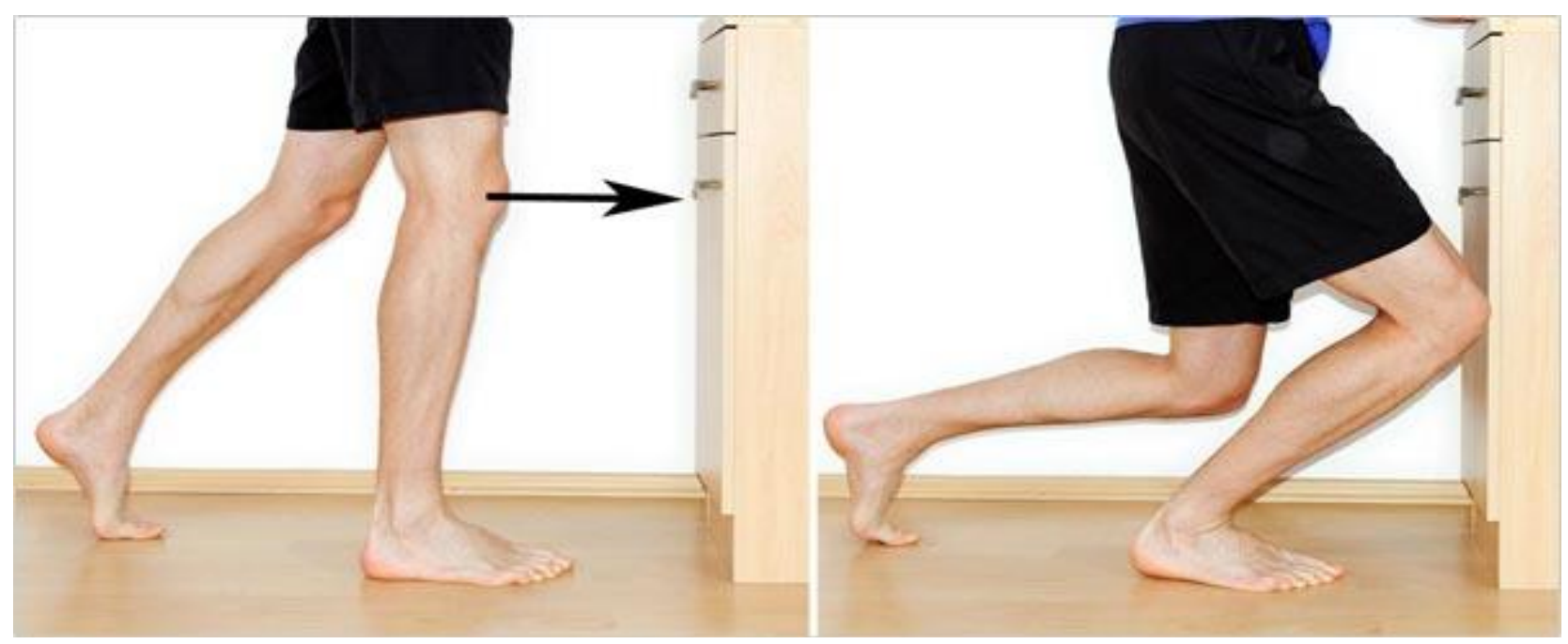

Figure 2. Analytical test: Ankle test.

\section{Work protocol}

The group of 12 athletes selected was subjected to a series of measurements:

1. Anthropometric measurements: height, weight, BMI.

2. Specific measurements: ankle dorsi-flexion.

All these measurements are shown below in Table 1. Speaking of Ankle test, previously, it was said that a value between 6 and 10 (speaking of $\mathrm{cm}$ away from the wall) are indicators of a probable ankle stiffness. The average of the reference group is $7.28 \mathrm{~cm}$ for the right ankle, while for the left ankle the average is $7.58 \mathrm{~cm}$. Therefore from the data it emerges that, on average, the whole selected group can incur in problems to the lower limbs sprung from a little mobile ankle. It is important to underline that, the data on the ankles, are the fruit solely and exclusively of the Ankle test, since, as an analytical test, it springs from the global observation of the selected subject. In an athlete who, globally, does not present anomalies in the execution of the Squat test, the analytical verification is superfluous. Therefore, the data on the flex backs obtained and reported derive, as already mentioned, exclusively from the Ankle test.

\section{Statistical analysis}

Data on the anthropometric characteristics, Squat test and Ankle test results will be presented as average and standard deviation (SD). The normality of data distribution will be verified with Kolmogorov-Smirnov test. t-test will be used to show the significant differences between before and post training. The significance level was set at $p<0.05$. Statistical analyses will be carried out with the software «IBM SPSS23». 


\section{RESULT}

Table 1. Anthropometric and functional data

\begin{tabular}{|l|l|l|l|l|l|l|l|}
\hline Athletes & Age & Height (cm) & Weight $\mathbf{( k g})$ & $\begin{array}{c}\text { Ankle } \\
\text { dorsiflexion DX* }\end{array}$ & $\begin{array}{c}\text { Ankle } \\
\text { dorsiflexion SX* }\end{array}$ & BMI & Data \\
\hline Athlete 1 & 18 & 175 & 65 & 7,8 & 8 & $21: 22$ & $19 / 12 / 2018$ \\
\hline Athlete 2 & 18 & 178 & 71 & 6,5 & 7,7 & $22: 41$ & $19 / 12 / 2018$ \\
\hline Athlete 3 & 15 & 169 & 70 & 7,8 & 9 & 24.51 & $19 / 12 / 2018$ \\
\hline Athlete 4 & 18 & 186 & 79 & 7,5 & 7 & 22.84 & $19 / 12 / 2018$ \\
\hline Athlete 5 & 18 & 174 & 68 & 7,7 & 8,9 & $22: 46$ & $19 / 12 / 2018$ \\
\hline Athlete 6 & 16 & 173 & 90 & 5,9 & 6,2 & 30.07 & $19 / 12 / 2018$ \\
\hline Athlete 7 & 16 & 187 & 65 & 8,2 & 7,9 & $18: 59$ & $20 / 12 / 2018$ \\
\hline Athlete 8 & 16 & 164 & 51 & 7 & 7,5 & 18.96 & $20 / 12 / 2018$ \\
\hline Athlete 9 & 16 & 184 & 70 & 5 & 5,8 & 20.68 & $20 / 12 / 2018$ \\
\hline Athlete 10 & 16 & 176 & 83 & 6,8 & 6 & 26.79 & $20 / 12 / 2018$ \\
\hline Athlete 11 & 18 & 178 & 70 & 8,2 & 8 & 22.09 & $20 / 12 / 2018$ \\
\hline Athlete 12 & 18 & 184 & 71 & 9 & 9 & 20.97 & $20 / 12 / 2018$ \\
\hline
\end{tabular}

In table 2 and figure 3 , the data obtained from the measurements before the administration of the work protocol are reported.

Table 2. Functional data A

\begin{tabular}{|l|c|c|}
\cline { 2 - 3 } & RIGHT ANKLE & LEFT ANKLE \\
\cline { 2 - 3 } ATHLETE 1 & 7,8 & 8 \\
\hline ATHLETE 2 & 6,5 & 7,7 \\
\hline ATHLETE 3 & 7,8 & 9 \\
\hline ATHLETE 4 & 7,5 & 7 \\
\hline ATHLETE 5 & 7,7 & 8,9 \\
\hline ATHLETE 6 & 5,9 & 6,2 \\
\hline ATHLETE 7 & 8,2 & 7,9 \\
\hline ATHLETE 8 & 7 & 7,5 \\
\hline ATHLETE 9 & 5 & 5,8 \\
\hline ATHLETE 10 & 6,8 & 6 \\
\hline ATHLETE 11 & 8,2 & 8 \\
\hline ATHLETE 12 & 9 & 9 \\
\hline
\end{tabular}




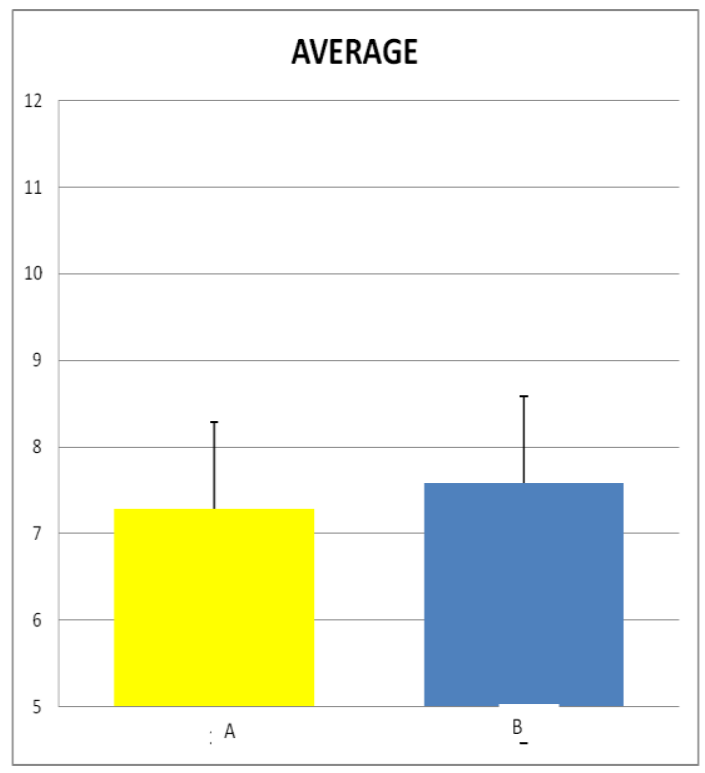

Figure 3. Functional data B

The athletes in the selected group have a reduced spine more pronounced flexion at the right ankle than the left ankle.

Once the aforementioned data have been obtained, the work protocol has been structured with a very specific sequence of exercises involving:

1. Mio-fascial release.

2. Mobility.

3. Proprioception.

4. Stretching.

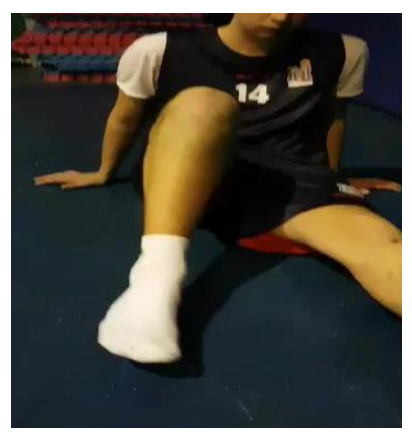

1. Mio-fascial release.

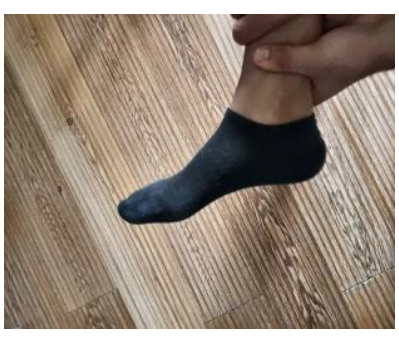

2. Mobility.
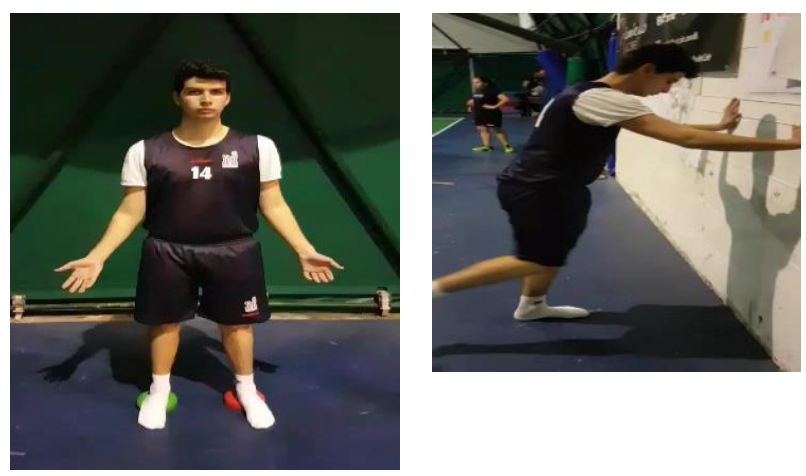

3. Proprioception.

4. Stretching. 
After 2 months of protocol administration, the data obtained showed the changed situation as reported in table 3 and figure 5 .

Table 3. Functional data B

\begin{tabular}{|l|c|c|}
\hline \multirow{2}{*}{ ATHLETE 1 } & RIGHT ANKLE & LEFT ANKLE \\
\hline ATHLETE 2 & 7,9 & 8 \\
\hline ATHLETE 3 & 6,9 & 7,9 \\
\hline ATHLETE 4 & 8,2 & 9,2 \\
\hline ATHLETE 5 & 8,9 & 7,3 \\
\hline ATHLETE 6 & 6,5 & 9 \\
\hline ATHLETE 7 & 8,4 & 6,4 \\
\hline ATHLETE 8 & 7,9 & 8 \\
\hline ATHLETE 9 & 6,4 & 7,8 \\
\hline ATHLETE 10 & 7 & 6,3 \\
\hline ATHLETE 11 & 8,2 & 6,3 \\
\hline ATHLETE 12 & 9 & 8,3 \\
\hline
\end{tabular}

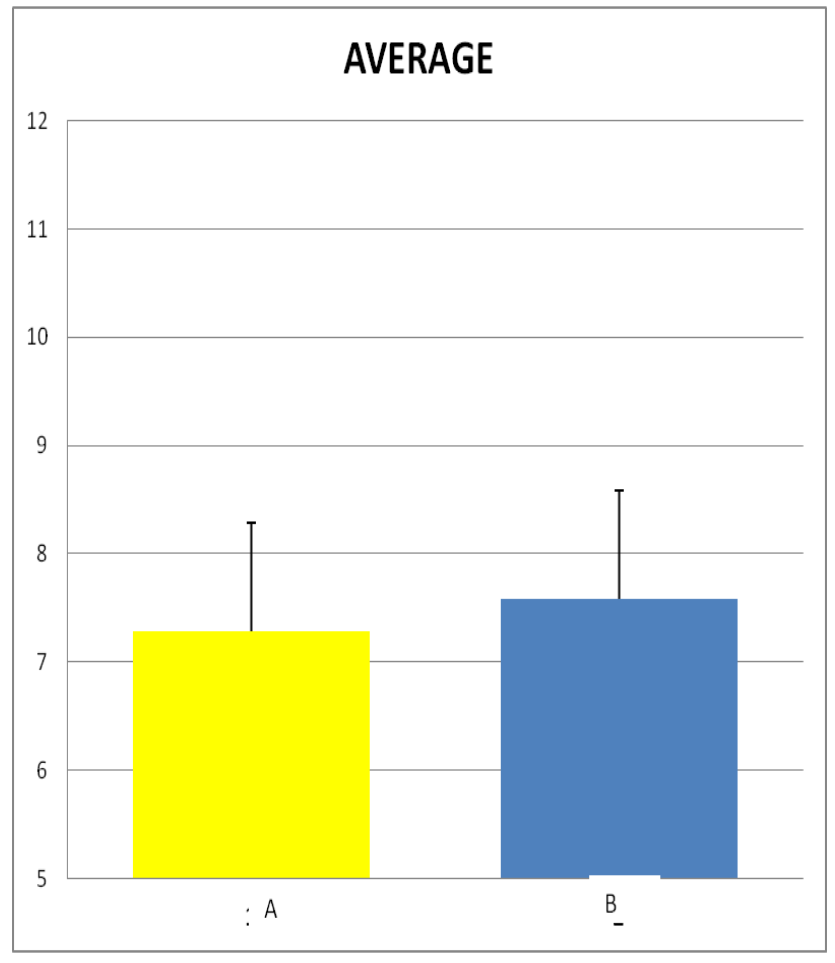

Figure 5. Functional data B. 
It is applied the Kolmogorov-Smirnov T-Test for pre and post protocol data normalization. The reference value for the verification was set at $p<0.05$. The statistical analysis was performed with the «IBM SPSS23» software.

Table 4. T-test right ankle

\begin{tabular}{|c|c|c|c|c|c|c|c|c|}
\hline & \multicolumn{5}{|c|}{ Coupled differences } & & \multirow{3}{*}{ gl } & \multirow{3}{*}{$\begin{array}{l}\text { Sign. (a } \\
\text { due code) }\end{array}$} \\
\hline & \multirow{2}{*}{ Average } & \multirow{2}{*}{ Dev. std. } & \multirow{2}{*}{$\begin{array}{l}\text { Average } \\
\text { standard error }\end{array}$} & \multicolumn{2}{|c|}{$\begin{array}{l}\text { Confidence interval of } \\
\text { the difference of } 95 \%\end{array}$} & & & \\
\hline & & & & Lower & Higher & & & \\
\hline $\begin{array}{l}\text { VAR01 } \\
\text { VAR02 }\end{array}$ &,- 40833 &, 40330 &, 11642 &,- 66458 &,- 15209 & $-3,507$ & 11 &, 005 \\
\hline
\end{tabular}

It is significant difference between the two right ankles with $p<0.05$.

Table 5. T-test left ankle

\begin{tabular}{|c|c|c|c|c|c|c|c|c|}
\hline & \multicolumn{5}{|c|}{ Coupled differences } & & \multirow{3}{*}{$g \mid$} & \multirow{3}{*}{$\begin{array}{l}\text { Sign. (a } \\
\text { due code) }\end{array}$} \\
\hline & \multirow[t]{2}{*}{ Average } & \multirow[t]{2}{*}{ Dev. std. } & \multirow{2}{*}{$\begin{array}{l}\text { Average } \\
\text { standard error }\end{array}$} & \multicolumn{2}{|c|}{$\begin{array}{l}\text { Confidence interval of } \\
\text { the difference of } 95 \%\end{array}$} & & & \\
\hline & & & & Lower & Higher & & & \\
\hline $\begin{array}{l}\text { VAR03 } \\
\text { VAR04 }\end{array}$ &,- 20833 &, 14434 &, 04167 &,- 30004 &,- 11663 & $-5,000$ & 11 &, 000 \\
\hline
\end{tabular}

It is significant difference between the two left ankles with $p<0.05$.

\section{DISCUSSION}

The data were collected in the same way for all the athletes, although on different days in some cases. The data collection procedure both before and after the work program has remained unchanged over time, so as to try to reduce as much as possible any errors in the measurements that would have altered the success of the research. It was particularly interesting, in my opinion, the case of the athlete number 12, who, despite having followed the protocol like all the other subjects, did not present any kind of improvement neither for the right ankle nor for the left ankle. Probably, the athlete number 12, needed the structuring of a different program in order to improve his mobility.

\section{CONCLUSIONS}

The protocol produced the desired results regarding the improvement of mobility, so the objective was achieved. The boys most suffering from problems in the lower limbs have benefited from it, at least during specific training sessions that involved stressing the ankles, during shooting sessions (Raiola, D'isanto, 2016) or in exercises without ball on speed or strenght (Izzo, R., Varde'i, C.H. 2018).

Clearly, these results should be observed over a much longer period, both off-season and in season, to better understand the real preventive function of a more mobile ankle (D'elia et al, 2019). 
This research has obtained results on a sample of young athletes, it could be interesting for the purposes of expanding and improving the research itself, proposing the same protocol on a group of older athletes or of the opposite sex to highlight the differences taking into account many other factors such as: age, sex, psychological state, emotional state, muscle mass, ability to stretch, state of training, etc.. (Altavilla et al, 2017). Even more interesting could be to discover the relationship between the anthropometric characteristics of these subjects and their sports performance (Altavilla et al, 2018), also taking into account the difference in role they have on the pitch, minutes of play at their disposal, mastery of game fundamentals (Altavilla, Raiola, 2014), without forgetting that, considering their young age (Ceciliani et al, 2005), probably not everyone has the same level of sports ability necessary for any sporting activity (Raiola, 2013). These considerations are obviously not the goal of this research, however, if you wanted to eliminate all the differences between the athletes, you should take into account each of them (Raiola, Di Tore, 2017).

\section{REFERENCES}

Altavilla, G., Raiola, G. (2019) A brief review on physiological commitment in basketball: An interpretative key, Journal of Human Sport and Exercise, 14, pp. S59-S65. https://doi.org/10.14198/ihse.2019.14.proc1.07

D'isanto, T. (2019) Physical and sport education between Italian academic system and European Research Council structure panel, Journal of Human Sport and Exercise, 14, pp. S66-S76. https://doi.org/10.14198/ihse.2019.14.proc1.08

D'Isanto, T., D'Elia, F., Raiola, G., Altavilla, G. (2019) Assessment of sport performance: Theoretical aspects and practical indications, Sport Mont, 17 (1), pp. 79-82.

Altavilla, G., D'Elia, F., Raiola, G. (2018) A breif review of the effects of physical activity in subjects with cardiovascular disease: An interpretative key, Sport Mont, 16 (3), pp. 103-106. https://doi.org/10.26773/smi.181018

Altavilla, G., Di Tore, P.A., Riela, L., D'Isanto, T. (2017) Anthropometric, physiological and performance aspects that differentiate male athletes from females and practical consequences, Journal of Physical Education and Sport, 17, art. no. 226, pp. 2183-2187.

Altavilla, G. (2016) Relationship between physical inactivity and effects on individual health status, Journal of Physical Education and Sport, 16, pp. 1069-1074.

Altavilla, G., D'isanto, T., Di Tore, P.A. (2018) Anthropometrics characteristics and jumping ability in basketball, Journal of Human Sport and Exercise, 13, pp. S385-S392. https://doi.org/10.14198/ihse.2018.13.proc2.22

Altavilla, G., \& Raiola, G. (2017). Physiological effects of warm-up and problems related to team sports, Sport Science, 10(2): 56-61.

Altavilla, G., \& Raiola, G. (2018). Periodization: finalization of the training units and of the load's entity. The European Proceedings of Social \& Behavioural Sciences EpSBS, 247-253. https://doi.org/10.15405/epsbs.2018.03.33

Altavilla, G., Raiola, G. (2014) Global vision to understand the game situations in modern basketball, Journal of Physical Education and Sport, 14 (4), art. no. 75, pp. 493-496.

Ceciliani, A., Di Carlo, M., Tentoni, C. (2005)Mental process learning Medicina dello Sport, 58 (1), pp. 43-52.

D'Elia, F., Mazzeo, F., \& Raiola, G. (2018). The core curriculum in the university training of the teacher of physical education in Italy. Journal of Human Sport and Exercise, 13(2proc), S413-S420. https://doi.org/10.14198/ihse.2018.13.Proc2.25 
D'Elia, F., D'Isanto, T., \& Altavilla, G. (2019). Training and performance in the transition period. Journal of Human Sport and Exercise, 14(2proc), S258-S262. https://doi.org/10.14198/ihse.2019.14.Proc2.15

D'Isanto, T., D'Elia, F., Raiola, G., Altavilla, G. (2019). Assessment of Sport Performance: Theoretical Aspects and Practical Indications, Sport Mont 17(1): 3-6. https://doi.org/10.26773/smi.190214

D'Isanto, T., Manna, A., Altavilla, G. (2017). Health and physical activity, Sport Science, 10(1):100-105.

Izzo, R., Varde'i, C.H. (2018)Experimental approach via three different protocols on the speed agility in basketball: A case study, Journal of Physical Education and Sport, 18 (2), art. no. 93, pp. 637-640.

Rago, V., Pizzuto, F., Raiola, G. (2017) Relationship between intermittent endurance capacity and match performance according to the playing position in sub-19 professional male football players: Preliminary results, Journal of Physical Education and Sport, 17 (2), pp. 688-691.

Raiola, G., D'elia, F., Altavilla, G. (2018) Physical activity and sports sciences between European Research Council and academic disciplines in Italy, Journal of Human Sport and Exercise, 13, pp. S283-S295. https://doi.org/10.14198/ihse.2018.13.proc2.13

Raiola, G. (2017) Motor learning and teaching method, Journal of Physical Education and Sport, 17, art. no. 236, pp. 2239-2243.

Raiola, G., Di Tore, P.A. (2017) Motor learning in sports science: Different theoretical frameworks for different teaching methods, Sport Science, 10, pp. 50-56.

Raiola, G., D'isanto, T. (2016) Descriptive shot analysis in basketball, Journal of Human Sport and Exercise, 11 (Proc1), pp. S259-S266. https://doi.org/10.14198/ihse.2016.11.proc1.18

Raiola, G. (2014) Teaching method in young female team of volleyball, Journal of Physical Education and Sport, 14 (1), pp. 74-78.

Raiola, G. (2013) Body knowledge and motor skills, Knowledge Cultures, 1 (6), pp. 64-72.

Raiola, G., Di Tore, P.A. (2017) Motor learning in sports science: Different theoretical frameworks for different teaching methods, Sport Science, 10, pp. 50-56.

Szymanski, D. (2001). Recommendations for the Avoidance of Delayed-Onset Muscle Soreness, J. Strength Cond. Res. 23(4): 7-13. https://doi.org/10.1519/1533-4295(2001)023<0007:rftaod>2.0.c0;2

Valentini, M., Bernardini, C., Beretta, A., Raiola, G. (2018a) Movement and language development as an early childhood twin strategy: A systematic review, Sport Mont, 16 (3), pp. 107-112. https://doi.org/10.26773/smi.181019

Valentini, M., Riccardi, F., Raiola, G., Federici, A. (2018b) Educational research: Motor area and relational area during children's personality development, Journal of Physical Education and Sport, 18, art. no. 327, pp. 2157-2174.

\section{(9) $(\mathbb{Q} \Theta \Theta$}

This work is licensed under a Attribution-NonCommercial-NoDerivatives 4.0 International (CC BY-NC-ND 4.0). 